\title{
Funções da avaliação da aprendizagem na formação inicial de professores de Ciências
}

\author{
Functions of learning evaluation in the initial formation of Science \\ teachers
}

\author{
Bruno Lamy Teixeira Diniz (bruno.lamy@ gmail.com) \\ Faculdade de Formação de Professores (FFP) - Universidade do Estado do Rio de Janeiro (UERJ) \\ Beatriz Pereira Jacques (jacques-bia@outlook.com) \\ FFP-UERJ \\ Tatiana Galieta (tatigalieta@gmail.com) \\ Departamento de Ciências - FFP-UERJ
}

Resumo: Apresentamos neste trabalho os resultados de duas pesquisas que buscaram identificar as diferentes visões de licenciandos em Ciências Biológicas a respeito da avaliação explorando suas funções no processo de ensino-aprendizagem. Os dados foram coletados em entrevistas com 27 licenciandos de um mesmo curso as quais foram, posteriormente, transcritas na íntegra. Foram utilizadas categorias teóricas para classificar as funções de avaliação enunciadas pelos sujeitos, a saber: diagnóstica, somativa, formativa e mediadora. Reflexões sobre a prova como método avaliativo surgiram nas falas dos entrevistados, desta forma, foi também incluída uma análise sobre suas limitações. Os resultados apontam uma lacuna em relação à avaliação diagnóstica que diz respeito aos conhecimentos prévios dos alunos. A função somativa como um reflexo de práticas classificatórias com tendências conservadoras esteve presente. As funções formativas e mediadoras também foram contempladas, já que os licenciandos expressaram preocupação com as estratégias de ensino, compreendendo a avaliação como um momento para refletir sobre a prática docente. Por fim, a prova foi identificada como um instrumento padronizado de avaliação que visa à normatização de práticas escolares e à exclusão de estudantes que se sentem pressionados e frustrados.

Palavras-chave: avaliação; ensino de ciências; formação de professores.

Abstract: In this paper we present the results of two researches that identified the different views of undergraduates in Biological Sciences regarding evaluation by exploring their functions in the teaching-learning process. Data were collected in interviews with 27 undergraduates of the same course. They were fully transcribed later. Theoretical categories were used to classify the evaluation functions stated by the subjects, namely: diagnostic, summative, formative and mediating. Reflections on the test as an evaluative method emerged in the interviewees' statements, so an analysis of their limitations was also included. The results point to a gap regarding the diagnostic evaluation that concerns the students' previous knowledge. The summative function as a reflection of classificatory practices with conservative tendencies was present. The formative and mediating functions were also contemplated, as the undergraduates expressed concern with teaching strategies, understanding the assessment as a moment to reflect on teaching practice. Finally, the test was identified as a standardized 
assessment instrument aimed at standardizing school practices and excluding students who feel pressured and frustrated.

Keywords: evaluation; science teaching; teacher training.

\section{INTRODUÇÃO}

A avaliação da aprendizagem foi proposta inicialmente por Ralph Tyler em 1930 através da metodologia de "ensino por objetivos" em que sugeria uma comparação das expectativas iniciais com os resultados alcançados a fim de desenvolver a melhor maneira de concluir os objetivos. Tyler, preocupado com o alto índice de reprovação dos alunos nos exames, desenvolveu uma avaliação em contraposição às examinações que se baseavam em determinar até onde os objetivos educacionais estariam sendo alcançados. Suas ideias sustentaram a base da Teoria Tecnicista, segundo a qual a escola melhorava a partir de um gerenciamento e a educação baseava-se na ideia de transferência direta dos conhecimentos. Assim como produziam novas máquinas e tecnologias, o aluno era um "produto", que deveria dominar aquilo que era considerado importante para que viesse a se tornar mão de obra eficiente (FREITAS, 1997).

A avaliação dentro do paradigma do tecnicismo assumia uma perspectiva meramente de verificação, em contraposição a uma função de acompanhamento da aprendizagem. A distinção entre avaliação somativa e formativa, em nível do currículo, foi inicialmente estabelecida por M. Screven somente em 1967 e, posteriormente, transposta para o âmbito da avaliação da aprendizagem por B. S. Bloom em 1969. Bloom, Hastings e Madaus (1971 apud GARCÍA-JIMÉNEZ, 2015) definem que a avaliação somativa tem a missão de atribuir valores às aprendizagens alcançadas pelo aluno ao término de um curso ou de uma de suas etapas, enquanto que a avaliação formativa tem o propósito de fazer a retroalimentação, permitindo realizar as correções necessárias durante o processo de ensino-aprendizagem.

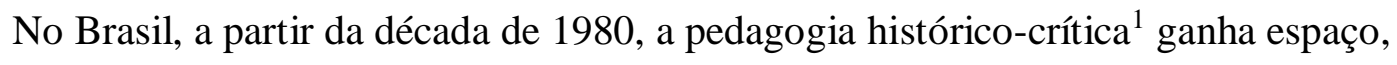
iniciando a discussão sobre avaliação em diferentes âmbitos e aspectos. Surgem, então,

\footnotetext{
${ }^{1}$ A pedagogia histórico-crítica tem sua base no materialismo histórico. De acordo com Saviani (2008), essa teoria busca "compreender a educação no seu desenvolvimento histórico-objetivo e, por
} 
pesquisas baseadas nas mais distintas tendências pedagógicas sobre o papel da avaliação. Hoffmann (1998) diz que o objetivo de debater a avaliação, na maioria desses estudos, baseava-se na tentativa de definir o principal significado da prática avaliativa dentro da ação educativa. A crítica à avaliação da aprendizagem como forma de exclusão e opressão aparece com destaque, fazendo-nos repensar seu papel na escola. Tais estudos preocupavam-se em situar o papel da avaliação dentro do ato de educar, a partir de uma visão contínua e formativa em que a avaliação não consiste apenas em um produto, mas sim consiste em parte fundamental do processo de ensino-aprendizagem. Como Hoffmann (1998, p. 20) destaca, "a avaliação deixa de ser um momento terminal do processo educativo" e se transforma "na busca incessante de compreensão das dificuldades do educando e na dinamização de oportunidades de conhecimento".

Acreditamos que reflexões sobre as finalidades da avaliação da aprendizagem devem estar presentes ainda na formação inicial dos futuros professores, de modo que não sejam reproduzidos modelos avaliativos que apenas cobram conteúdos isolados dos estudantes. Luckesi (2008, p. 46) afirma que um educador que está preocupado com uma prática educacional transformadora não pode "agir inconscientemente e irrefletidamente", pois sua ação deve ser explícita tendo em vista o "que está fazendo e para onde possivelmente está encaminhando". E completa:
A avaliação, neste contexto, não poderá ser uma ação mecânica. Ao contrário, terá de ser uma atividade racionalmente definida, dentro de um encaminhamento político e decisório a favor da competência de todos para a participação democrática da vida social (LUCKESI, 2008, p. 46).

Nesse sentido, entendemos que a formação inicial de professores de Ciências e Biologia deve criar espaços para se (re)pensar os processos avaliativos. Neste artigo apresentamos os resultados de duas pesquisas (LAMY, 2017; JACQUES, 2018) que tiveram como cenário empírico o curso de licenciatura em Ciências Biológicas da Faculdade de Formação de Professores (FFP) da UERJ e como sujeitos de pesquisa seus estudantes. Nosso objetivo consistiu em analisar as visões sobre avaliação da compromisso, seja a transformação da sociedade e não sua manutenção, a sua perpetuação" (p. 93). 
aprendizagem desses licenciandos focando em suas funções e na prova como método avaliativo.

\section{FUNDAMENTAÇÃO TEÓRICA}

A avaliação da aprendizagem possui, de acordo com Kraemer (2005), três funções principais: diagnóstica, somativa e formativa.

A avaliação diagnóstica é realizada no início do processo de ensinoaprendizagem, pois tem objetivo identificar o conhecimento que os alunos trazem consigo. Dessa forma, o avaliador passa a ser capaz de diagnosticar as dificuldades que os alunos poderão ter no decorrer do ano letivo (KRAEMER, 2005). A avaliação diagnóstica pretende averiguar como o aluno se comporta, quando se depara com as novas aprendizagens, buscando sanar dificuldades do presente e prever dificuldades futuras. De acordo com Blaya (2009), para obter-se um bom resultado a partir da utilização deste tipo de avaliação é preciso estar bastante atento a não atribuir "rótulos" negativos àqueles alunos que demonstram maior dificuldade, que não atendem as expectativas do avaliador, buscando ajudá-los a atingirem a aprendizagem com mais facilidade. A utilização de provas e testes pode não ser a melhor opção para esta função avaliativa, Luckesi (2011) nos fala que, para obtermos um diagnóstico do que o estudante já aprendeu, é importante explorarmos outros instrumentos que nos possibilite conhecer suas vivências e os conceitos que carregam, motivando reflexões a respeito dos assuntos, tendendo a uma avaliação crítica sobre os dados obtidos. A função diagnóstica gera uma organização de ideias que facilitem o trabalho do professor na elaboração de metodologias para desenvolver o aprendizado, os conteúdos que serão dados, uma meta a ser atingida e a escolha de um processo de avaliação posterior (SILVA e SCAPIN, 2011).

Segundo Kraemer (2005), a avaliação somativa tem o propósito de classificar os estudantes ao final de um período de aprendizagem, de acordo com os níveis de aproveitamento de cada um. Isso quer dizer que depois do processo de ensino de determinado conteúdo, o aluno é sujeito a uma avaliação que vai indicar o nível de aprendizagem que ele conseguiu obter, através de uma nota ou conceito. Esta metodologia é a mais tradicional, na qual os testes e as provas são mais comumente 
utilizados como objeto de registro, pois centraliza o potencial de comando nele que, por sua vez, estabelece a posição que os alunos atingiram através de médias aritméticas em relação aos objetivos previamente planejados por ele (WACHOWICZ, 2000).

A avaliação formativa propõe investigar se o aluno está atingindo os objetivos no decorrer do período de aprendizagem, a fim de distinguir as dificuldades de compreensão, permitindo que o professor corrija os erros e dê suporte para que se recupere através de um mecanismo de "feedback" (KRAEMER, 2005). Neste processo, o próprio aluno pode também se atentar em onde está tendo maior dificuldade para que assim se dedique mais e alcance um melhor resultado em sua aprendizagem. Neste momento o ato de avaliar deixa de ser uma forma de julgar o aluno sobre seus conhecimentos, passando a ser uma forma de enxergar o caminho que o estudante já trilhou e que ainda deve trilhar para a construção do seu conhecimento (ESTEBAN, 2003). Além disso, em uma avaliação formativa o estudante assume papel ativo no processo avaliativo, pois ela "tendo como foco o processo de aprendizagem, numa perspectiva de interação e de diálogo, coloca também no estudante, e não apenas no professor, a responsabilidade por seus avanços e suas necessidades" (FERNANDES e FREITAS, 2007, p. 22).

Além dessas três funções, Hoffmann $(1998 ; 2014)$ propõe o conceito de avaliação mediadora. Como o próprio nome já diz, ela se faz através de uma mediação constante, ou seja, um acompanhamento permanente do professor que, por meio de uma articulação direta com os estudantes, buscará a compreensão dos saberes, as dificuldades de assimilação, entender como e o porquê deles pensarem de uma determinada maneira. Neste tipo de avaliação o professor deve:

Oportunizar aos alunos muitos momentos de expressar suas ideias; Oportunizar discussões entre os alunos a partir de situações problematizadoras; Realizar várias tarefas individuais, menores e sucessivas, buscando entender as respostas apresentadas pelos estudantes; Em vez do certo/errado e da atribuição de pontos, fazer comentários sobre as tarefas dos alunos, auxiliando-os a localizar as dificuldades, oferecendo-lhes oportunidades de descobrirem melhores soluções; e transformar os registros de avaliação em anotações significativas sobre o acompanhamento dos 
alunos em seu processo de construção de conhecimento (HOFFMANN, 2014, p. 73-85).

A avaliação mediadora, portanto, ainda que tenha um viés formativo no qual o estudante também tem papel ativo em sua avaliação ao longo do processo de ensinoaprendizagem, requer um acompanhamento individual do professor desde $\mathrm{o}$ planejamento das atividades até o retorno dado ao aluno.

Tradicionalmente alguns métodos avaliativos têm sido empregados de acordo com as funções dos processos avaliativos. O mais reconhecido deles é a prova (escrita ou oral) utilizada como um recurso de aferição de conhecimentos em uma avaliação essencialmente somativa. Por outro lado, o uso de debates, discussão de textos, seminários, produção de materiais diversos (como vídeos, modelos e redações), aulas prático-investigativas têm mais espaço em avaliações formativas e mediadoras. As provas, não necessariamente, são instrumentos de examinação que, de acordo com Luckesi (2008) é uma forma excludente e estática de classificação em um ranking, porém elas têm sido usadas basicamente com o intuito de selecionar os "capazes, detentores do conhecimento" excluindo os "não aptos a serem promovidos à próxima série escolar".

Atualmente a prova tem sido largamente utilizada com o propósito de quantificar o conhecimento adquirido pelo estudante. De acordo com Neto e Aquino (2009), na maioria das escolas, o professor age de forma limitada: ele transmite o conhecimento, formula uma avaliação, geralmente uma prova, e corrige-a a fim de quantificar quanto o aluno "aprendeu" do conteúdo ensinado naquele período. Ainda para essas autoras, isso acontece sem nenhum elo de continuidade, sem nenhum tipo de progressão na construção do conhecimento. Outra grande influência comum na prática dos educandos são as provas padronizadas, tanto nas redes públicas, quanto nas escolas particulares; provas estas, que os professores não têm a opção de aplicar ou não. O professor não possui autonomia para selecionar e ministrar os conteúdos já que essas provas chegam prontas até ele.

Dentro deste cenário autoritário e pouco democrático, a prova ganhou o papel de "vilã" na escola gerando medo e apreensão por parte dos estudantes. De acordo com Souza (2009, p. 19), “a prova é o principal instrumento de controle e disciplinarização 
da pedagogia tradicional, os testes e as provas transformam-se num recurso de ameaça e submissão dos educandos". Logo, os sentimentos dos estudantes com relação às provas dificilmente são agradáveis por estas despertarem ansiedade e repulsa. Desta forma, consideramos fundamental que os professores em formação inicial rememorem as experiências vivenciadas quando na época de estudantes para que, munidos de um arcabouço teórico, possam refletir e orientar suas práticas avaliativas de modo a superar os usos tradicionais da prova.

\section{METODOLOGIA}

As pesquisas que deram origem a este manuscrito podem ser situadas no campo das pesquisas sociais de natureza qualitativa. Ambas abordaram aspectos relativos ao homem em seus múltiplos relacionamentos com outros homens (estudantes e professores) e instituições sociais (escolas e universidades) (GIL, 1987). Considerando a pesquisa social como essencialmente qualitativa, por se preocupar com um nível da realidade que não pode ser quantificado, buscamos compreendê-la pela aproximação e interpretação dos dados produzidos em situação empírica (MINAYO, 1994).

Os instrumentos utilizados nesse processo investigativo foram entrevista semiestruturadas, as quais, segundo Lüdke e André (2012), possuem um esquema que melhor se adapta aos estudos do ambiente educacional já que permite maior abertura aos sujeitos. As entrevistas ocorreram nos meses de novembro e dezembro de 2016 e em setembro de 2017. No total foram entrevistados 27 licenciandos de várias turmas matriculados entre os períodos de 2011-1 e 2013-2 de um mesmo curso de Licenciatura em Ciências Biológicas de uma universidade pública do Estado do Rio de Janeiro. As entrevistas tiveram duração em torno de 20 minutos, foram gravadas e, posteriormente, transcritas na íntegra. Todos os participantes receberam um Termo de Consentimento Livre e Esclarecido contendo os objetivos das pesquisas e o compromisso, por parte dos pesquisadores, em não divulgar os nomes reais dos sujeitos.

Os roteiros das entrevistas tinham oito e sete questões, cada um. Apesar das duas pesquisas terem tido objetivos gerais distintos, três perguntas eram comuns, a saber: 1) O que você compreende por avaliação? 2) Como suas experiências anteriores ajudaram a moldar esta visão de avaliação que você tem hoje? 3) Como sua formação no curso de 
licenciatura ajudou você a pensar sobre a avaliação? A partir das respostas a essas questões buscamos identificar as quatro funções da avaliação da aprendizagem utilizadas aqui como categorias de análise delimitadas a partir do referencial teórico da pesquisa (KRAEMER, 2005; HOFFMANN, 1998; 2014).

Além dessa categorização, buscamos compreender os papeis que foram atribuídos à prova enquanto método avaliativo devido à sua recorrente presença nas falas dos entrevistados. Assim, apoiados em autores como Moretto (2001) e Souza (2009) tentamos localizar as origens destas compreensões e caracterizar as finalidades e as limitações da prova segundo os licenciandos. Os resultados são, portanto, divididos em duas seções referentes às funções da avaliação da aprendizagem e ao papel da prova no processo avaliativo.

\section{RESULTADOS}

\subsection{As funções da avaliação da aprendizagem}

Nenhum dos entrevistados sinalizou a função da avaliação diagnóstica na primeira etapa do processo de ensino-aprendizagem. Isso aponta uma lacuna importante em sua formação já que os estudos sobre concepções alternativas no ensino de Ciências, que existem desde a década de 1970, sinalizam a necessidade de que o professor estabeleça um diálogo com seus alunos, questionando-os sobre determinado fenômeno natural.

Para fazer frente a estes questionamentos, os alunos geralmente usam os seus pré-conhecimentos, muitas vezes baseados no senso comum, para responder a indagação de seus professores. É a partir das respostas dos alunos que o professor tem possibilidade de reelaborar sua aula, estabelecendo uma ponte a partir das "hipóteses" apresentadas pelos estudantes até o conhecimento científico (HOFFMANN et al., 2017, p. 92).

Desta forma, a sondagem das concepções dos alunos assumiria a função de avaliação diagnóstica nas aulas de Ciências. Logo, este resultado aponta a necessidade de que seja abordada esta relação em cursos de licenciatura em Ciências Biológicas.

Encontramos nas falas dos licenciandos a visão relacionada à medida ou mensuração da aprendizagem após o processo de ensino própria da avaliação somativa. 
Há um entendimento de que o aprendizado pode ser quantificado e a ele deve ser atribuído um número, um conceito, uma nota.

É a forma de mensurar alguma coisa, que você queira medir. (Miguel)

Avaliação é toda forma de checar ou verificar o conhecimento do aluno sobre aquilo que foi dado. (Vagner)

Avaliação é uma medida de testar o conhecimento, seja como for, seja quantificar o quanto você sabe. (Vicente)

De modo geral é a forma de um aluno ter uma nota, um número, pra passar na disciplina ou numa matéria. (...) Medir a capacidade de alguém. (Fernando)

Método de medir o conhecimento. (Rafaela)

(...) você tem os seus critérios de avaliação que aí você vai tirar o seu conceito e sua nota de acordo com os critérios para saber se o aluno conseguiu corresponder de forma mediana ou ótimo àquilo que foi proposto. (Dário)

Avaliação é, basicamente, testar conhecimentos. Testar o que o aluno, de fato, conseguiu absorver do que o professor quis passar. (Fabrício)

Os licenciandos acima atribuíram à avaliação uma função quantitativa como se sua função fosse atribuir um número, um nível que classifica os alunos em uma espécie de medida pré-determinada. De acordo com Sant'anna (2013), isso não seria um problema caso os professores considerassem tais avaliações como métodos que garantem a evolução progressiva do saber dos alunos. Não podemos definir esta forma de pensar como certa ou errada, mas a presença única da função somativa, quando as demais possibilidades são excluídas, pode indicar uma limitação no processo avaliativo que poderá, inclusive, ser algo prejudicial para o aprendizado do estudante.

A avaliação formativa esteve presente nas falas da maioria dos licenciandos apontou a avaliação como sendo uma forma de confirmar o aprendizado do aluno ao longo do processo de ensino-aprendizagem, como vemos nas falas abaixo:

(...) eu acho que também é uma forma de você ver as dificuldades que eles estão tendo. (Raquel)

Envolve avaliar o desempenho do aluno, em um determinado momento, sobre um determinado conteúdo. (Jorge) 
Seria uma forma da gente ver se o aluno aprendeu aquilo? O que foi passado pra ele?(...), mas uma forma da gente identificar o que ele aprendeu daquela matéria, e se aprendeu. (Thamires)

(...) é você observar, de modo geral, falando do aluno, o aluno no dia a dia. Isso é uma avaliação. Se eu for resumir eu vou dizer que é uma coleta de informações. (Rita)

Método avaliativo é você ficar observando o aluno, ver como ele se sai nos aprendizados, aquilo que ele tem mais dificuldade e o que ele não tem tanta dificuldade (...) seria mais você ver como o aluno age. (Giovana)

Acho que avaliar é mais do que um papel, do que aquelas perguntas ali. Tem todo um processo de sala de aula, de observação e tudo mais. (Marina)

Avaliação, pra mim, é qualquer método que você possa utilizar para analisar se o aluno está compreendendo, ou não, determinado assunto. (Janaina)

Para Blaya (2009), a avaliação formativa baseia-se na ideia de coletar informações para que haja uma reorientação do processo de ensino-aprendizagem. A autora utiliza a expressão "bússola orientadora" para dar a ideia de que a avaliação é o que vai orientar o professor no melhor caminho a seguir, objetivando sempre a construção do conhecimento. Para os licenciandos acima, o professor precisa estar atento a todas as ações do estudante, a cada dificuldade colocada por ele, para que possa existir um processo de acompanhamento contínuo com a avaliação atrelada ao dia a dia do aluno.

Dentre todos os entrevistados, somente uma licencianda elaborou uma definição próxima do conceito de avaliação mediadora, conforme proposto por Hoffmann (2014). A futura professora identificou a possibilidade de utilizar diversos fatores como: o interesse do aluno, a participação, o comportamento e até mesmo a procura do aluno pelo professor com a intenção de tirar dúvidas referentes aos assuntos abordados na aula.

Avaliação me remete a analisar alguma competência de algum objeto, mas a avaliação pode ser feita de diversas formas. Todos logo pensam em prova, mas não, pode ser uma atitude de alguém em sala de aula, uma resposta que o aluno mesmo deu durante a aula a uma pergunta, pode ser um trabalho qualquer ou até mesmo o fato de o aluno te procurar para tirar duvidas com você. A todo momento as pessoas avaliam coisas de acordo com critérios que ela tem. (Renata)

Nesta fala, a licencianda Renata ressalta a importância de que as avaliações ocorram a todo o momento, tanto durante as aulas quanto na realização de atividades, pois o professor deve acompanhar a evolução dos alunos, guia-los e estimular uma 
forma de pensar questionadora que os façam compreender as informações a partir do seu próprio senso crítico.

Além das funções identificadas anteriormente, a noção de que a avaliação deve servir como um momento reflexão do professor sobre sua própria prática apareceu fortemente nas falas dos licenciandos. Segundo os entrevistados, o professor pode utilizar o processo avaliativo para avaliar o seu trabalho, não apenas o aprendizado de seus alunos.

Eu acho que muitas vezes a avaliação serve para avaliar o seu trabalho, com base nos objetivos que você produziu. (...) Pra você ver o que precisa ser mudado, o que aconteceu pra você não conseguir cumprir o seu objetivo, aonde você falhou, né? (...) Ou se a sua avaliação foi bem-sucedida, (...) você vai saber que você tá no caminho certo. (Jorge)

(...) é uma avaliação do meu trabalho. A prova eu acho que funciona muito mais pra mim, do que para o aluno. (...) Uma boa avaliação pra mim, é também para avaliar a forma como eu estou trabalhando. (Rita)

A gente como professor, no início do ano letivo, vai pensar o que quer alcançar com os alunos, e durante o ano a gente tem que ir testando pra ver se tá sendo alcançado ou não, e essas avaliações vão servir para isso. (Gustavo)

(...) também é uma forma de você saber se, a forma com que você está ensinando, está sendo aceita. (...) se tá sendo clara pros alunos, se eles conseguem entender o que você está querendo ensinar para eles. (Camila)

(...) eu acho que também é uma forma de você saber se eles entenderam a matéria, e as dificuldades que eles estão tendo, e tentar então melhorar a didática em sala de aula, ver umas novas formas de metodologia de ensino. (Raquel)

No sentido de ensino e aprendizagem eu acho que é um termômetro para o professor. (...) Saber se aquela turma tá com algum problema, talvez, por que pode ser um problema até com o professor. Eu acho que avaliação é mais para o professor do que pro próprio aluno. (Karla)

(...) se aquilo que você passou realmente foi entendido, ou o que você precisa realmente melhorar. E aí cabe a você saber se o seu método foi eficaz, se cabe a você intervir de outra forma (...). (Mário)

Os formandos percebem a importância de estabelecer objetivos, dentro do processo de ensino-aprendizagem, principalmente para que o professor não realize avaliações que se limitem à aquisição de conhecimentos pelo estudante. A avaliação, nesse sentido, serve ao professor para identificar se seus propósitos previamente estabelecidos foram alcançados ou não, realizando, assim, uma avaliação de suas 
próprias estratégias didáticas. Esta ideia vai ao encontro do que Gaspar e Levandovski (s/d) destacam: "a avaliação deve ter como objetivo a qualidade da prática pedagógica do professor" e não apenas mirar no que foi aprendido pelo aluno, servindo, assim, como um "parâmetro da práxis educativa" (p. 2).

\subsection{O papel da prova no processo avaliativo}

Os licenciandos trouxeram reflexões sobre a prova como um método avaliativo, enquanto dissertavam sobre suas visões de avaliação no processo de ensinoaprendizagem. É importante ressaltar que não foi feita qualquer pergunta específica aos entrevistados sobre esse tema, o que revela a relevância da prova para os sujeitos da pesquisa.

Os licenciandos disseram que suas visões sobre avaliação são oriundas da escola, quando ainda eram estudantes da educação básica. Eles sinalizaram que as formas como foram avaliados por seus professores de ensino médio e fundamental influenciaram, direta ou indiretamente, suas maneiras de pensar o tema. Nessas falas, a prova aparece como o principal método avaliativo.

Como aluno tive provas ou trabalhos que me deram notas e essa é a forma que sempre fui avaliado (...). (Fernando)

Essa concepção vem desde a época de colégio (...) (Vagner)

É o que eu vejo meus professores fazendo, o modelo que os vejo pondo em prática. Desde o ensino fundamental, médio e até na faculdade. (Rafaela)

(...) na escola eu me lembro muito bem que eu tinha trabalhos, mas nenhum professor falava pra mim que aquilo era um método avaliativo, então, pra mim, os trabalhos eram um complemento da minha nota pro caso de eu ir mal na prova. (Renata)

Como aluna eu tive varias experiências porque eu estudei num colégio onde se trabalha com vários métodos avaliativos, incluindo a prova. (Janaína)

$\mathrm{Na}$ fase do ensino fundamental e médio eu via sempre como uma coisa de teste mesmo (...). (Wilson)

É, lembrando da época do colégio, era só prova escrita, e ficava baseado naquilo ali. E aquilo rotulava um pouco né? Eu aprendi a não ligar muito para esse rótulo que a prova dá pra gente né. Se a nota é boa, é um bom aluno, nota ruim, ruim aluno. (Paulo) 
Os modelos pedagógicos que vivenciamos ainda quando estudantes (considerados saberes docentes oriundos da formação escolar, de acordo com Tardif (2002) exercem forte influência sobre as práticas docentes. Por isso, é fundamental que os futuros professores estejam conscientes sobre os modelos pedagógicos que possuem para que eles sejam desconstruídos sistematicamente ao longo das disciplinas pedagógicas cursadas na graduação Nesse sentido, a formação inicial apareceu positivamente como sendo um espaço de reflexão sobre a avaliação. De acordo com alguns entrevistados, suas visões com relação à avaliação e à prova, mais restritamente, foram modificadas após discussões em disciplinas da licenciatura.

No meu ensino médio eu achava que avaliação era só prova e trabalho, já aqui na faculdade mudou um pouco, mas acho que poderia mudar mais (...). (Vicente)

(...) Antes, no ensino médio, até eu chegar aqui, eu achava que avaliação era só prova, tanto que quando alguém fala, que vai ter uma avaliação, você já pensa logo em prova. (Ester)

Eu tinha uma visão antes de entrar aqui de que avaliação poderia ser qualquer tipo de qualquer outra coisa (...) a minha visão era um pouco rudimentar em relação a isso. Claro que quando falava em uma avaliação me remetia à prova, mas eu sabia que não era só aquilo, e aqui eu consegui através de várias disciplinas, entender o quão importante é uma avaliação, e saber, tá, então se não vai ser prova eu vou avaliar como? Sabe? Então eu acho que as disciplinas me deram recursos pra entender, como fazer diferente né, já que prova não é somente o único, e nem sempre o mais eficaz meio de avaliar alguém, então eu acho que foi moldada aqui, né, foi construída aqui. (Mário)

Antes de eu entrar aqui, como eu estava acostumada com a escola, eu tinha a noção de avaliação ser só prova, só prova escrita, e pronto. Depois que a gente vem pra cá, a gente começa a ter uma noção de que avaliação é além disso, pode ser de diversos tipos, tanto que a gente já falou, além de trabalhos, de discussões, não só a prova escrita. Até por que a prova não diz muita coisa né, por que as vezes o cara é um bom aluno e não vai bem nas provas, e o outro que não é, vai bem, por que é só estudar um pouco antes, então, nem sempre a prova é um método muito bom de avaliação. (Thamires)

Como por exemplo a questão da prova e avaliação, como se um sistema de avaliação. (...) Eu lembro de um professor de Filosofia, ele é completamente crítico a prova como avaliação, assim, realmente, você pensar do jeito dele, (...) eu também acabei incorporando essa forma crítica, como a prova como avaliação. Mas a gente sabe que o sistema funciona assim né? Não é como a gente quer. Eu acho que não é o melhor, não é o melhor. Existem outras formas, a prova também é uma forma eficaz, mas existem melhores. (Miguel)

Os licenciandos citaram diferentes disciplinas, tais como: Metodologia do Ensino de Ciências e Biologia, Didática, Estágio Supervisionado, Filosofia da Educação e 
Políticas Públicas e Educação, que discutiram aspectos sobre práticas avaliativas (JACQUES, 2018). Isso demonstra que esse curso de licenciatura em Ciências Biológicas tem explorado o tema, ainda que os entrevistados não tenham mencionado autores específicos que tenham sustentado as discussões.

Encontramos, ainda, falas sobre a prova que podem ser consideradas como opostas, ora ressaltando sua importância ora destacando uma posição contrária ao seu uso.

\begin{abstract}
Eu acho que o modo como a gente avalia hoje em dia, o modo como o governo e todo o resto tenta avaliar, em prova, não é uma avaliação válida em nenhum quesito. Eu não acho válido. Antigamente eu achava que você dava uma prova, eu achava que aquilo era suficiente, por que o aluno deveria aprender aquilo que você deu (...). (Giovana)
\end{abstract}

Eu acho que assim, tem que ter a parte da prova, da avaliação escrita, por que eu vejo muito isso na gente mesmo. Eu tive professor que fazia qualquer outra atividade, sei lá, algum trabalho, alguma coisa, e a gente acabava não sabendo escrever, sabe? (Marina)

A licencianda Giovana traz uma questão importante sobre a prova que é a padronização das avaliações em larga escala feitas por órgãos públicos educacionais, tema este que está longe de ser consensual dentro do meio educacional (BAUER et al., 2015). Por outro lado, a licencianda Marina destaca o aspecto da escrita como uma habilidade que também deve ser exercitada durante a avaliação. A ideia da licencianda vai ao encontro do que Moretto (2001) diz sobre a perspectiva construtivista de avaliação que vai defender o uso de textos nas provas que obriga a leitura (ainda que curta) e provoca uma resposta escrita e argumentada, levando o aluno a exercitar a lógica e a correção do texto.

Vários dos entrevistados enfatizaram que a prova deve ser considerado um entre tantos métodos avaliativos, retirando dela seu protagonismo na educação formal ou indicando a não precisão da prova como instrumento avaliativo.

E aí você tem vários outros fatores né? Seja em prova, avaliação no colégio, ou avaliação, sei lá, de desempenho, qualquer outra coisa. Não precisa ser prova, pra passar de ano. (Paulo)

Eu acho que deveria existir uma preocupação em tomar a prova como única avaliação. Eu acho que existem outras formas de se avaliar os alunos, e não sei quem sou eu pra dizer que prova, só prova, é errado, mas eu acho que é 
preciso desconstruir essa coisinha de que existe só prova pra avaliação. (Gustavo)

E uma prova não necessariamente é uma avaliação. Eu não considero uma prova necessariamente uma avaliação, apesar de ser um bom método de você obter nota, mas nem sempre vai condizer com a minha avaliação. Às vezes eu avalio muito bem um aluno, mas ele não, não alcança a nota suficiente. (Rita)

Então, pensar que eu posso fazer isso de diferentes formas já me fez repensar também a prova como ferramenta de avaliação, onde até desmistificou um pouco, por que eu já estava até totalmente contra né, a utilizar prova como ferramenta de avaliação. Mas se você pensar, assim, até dá pra utilizar ela de uma maneira melhor. (Jorge)

(...) comecei a perceber que a avaliação como prova só escrita não era uma forma justa de você avaliar todo mundo, então eu nunca gostei (...). (Thaiane)

Os licenciandos cujas falas foram transcritas acima indicam atenção às diferentes formas de aprendizado que devem ser contempladas em uma diversidade de métodos avaliativos. Segundo Alípio e Galieta (2018), os próprios estudantes têm dificuldades em reconhecer outras formas de avaliação (como a produção de vídeos, modelos didáticos e participação em feiras de ciência) para além da prova nas aulas de ciências. Os resultados apontam que os futuros professores estão atentos à necessidade de diversificação dos instrumentos avaliativos e de mudança de postura com relação à exclusividade e ao status da prova no ensino de Ciências.

Outro aspecto presente nas falas dos licenciandos diz respeito ao componente emocional das provas, no qual enfatizam a pressão e o medo atrelado a elas. Eles mencionaram, inclusive, exemplos de situações pessoais.

Eu acho que tem muitos alunos que até por medo, de ser uma prova, talvez eles não vão tão bem como eles iriam se fosse talvez um exercício em sala de aula. (Camila)

Eu, particularmente, não gosto muito desse tipo de avaliação que a escola faz, de prova. Por que eu acho que só o nome prova, já traz uma carga muito pesada. (Karol)

Como aluno eu tinha um medo de ser avaliado, porque eu via como uma imposição, você precisa aprender aquilo de qualquer forma, de você sentar, decorar fórmulas e nomes, meio punitivo e imposta pelo professor do que propriamente você ter uma avaliação natural. (Dário)

(...) hoje em dia eu vejo que a prova é um método muito falho de avaliação. Primeiro pela pressão, você está forçando o aluno a estudar uma quantidade absurda de conhecimento pra não usar todo esse conhecimento na prova e 
nem sempre o aluno consegue absorver aquilo porque o aluno está desesperado para estudar para a prova (...). (Fabrício)

(...) utilizar só uma forma de avaliação é negligente com os alunos, porque eles se portam e sofrem pressão de maneira diferente com os métodos avaliativos. (Nicole)

Como aluno, eu estava fazendo uma prova, a professora tinha plena certeza que eu sabia a matéria, sentei com os alunos, expliquei a matéria pra todos eles, só que, na hora que eu fui fazer a prova eu tive um surto e deu branco e não consegui responder nada na prova. Então a professora saiu catando prova onde não tinha pra tentar me dar uma pontuação para não me prejudicar, porque ela sabia que eu sabia a matéria. (Nuno)

No dia da prova o aluno podia estar passando mal, ou podia ter ficado passando mal na noite anterior e foi fazer a prova em péssimo estado, mas isso não significa que ele não sabe a matéria, mas que não estava conseguindo realizar a atividade naquele momento, mas que podia realizar em outro momento. (Janaína)

Os entrevistados ressaltam que os alunos sentem a pressão, um medo, que atrapalha no resultado gerado pela prova. Este medo pode causar sequelas graves no educando como, por exemplo, o desinteresse pelos estudos, a raiva canalizada em um mau comportamento em sala de aula ou até mesmo um quadro de depressão e frustração que pode culminar com o abandono escolar (DINIZ, 2017). O medo por vezes está relacionado à utilização da prova como ameaça aos alunos quando o professor a usa como um instrumento disciplinador (SOUZA, 2009). Logo, o caráter punitivo que a prova tem, em vez de auxiliar no processo contínuo da aprendizagem, sanando dúvidas do aluno e auxiliando-o a identificar suas dificuldades na aprendizagem. Acreditamos que essas tradições relacionadas à prova tenha culminado com falas dos licenciandos que expressam a forte resistência a este método avaliativo.

\section{CONSIDERAÇÕES FINAIS}

Os resultados das pesquisas apontam para a dificuldade dos licenciandos em perceber a avaliação em um momento anterior às aulas como um instrumento de sondagem que lhes permitiria elaborar métodos capazes de suprir eventuais deficiências durante a aprendizagem. A função diagnóstica da avaliação (KRAEMER, 2005) aparece como uma lacuna na formação inicial desses futuros professores o que indica a necessidade de ampliação da discussão dos modelos avaliativos nas disciplinas 
pedagógicas do curso. No caso específico de uma licenciatura em Ciências Biológicas consideramos essencial abordar o tema estabelecendo um diálogo com o movimento das concepções alternativas no ensino de Ciências (HOFFMANN et al., 2017).

A função somativa (KRAEMER, 2005) que esteve presente nas falas de alguns licenciandos surgiu como o reflexo de um modelo amplamente utilizado nas escolas e universidades. Essa visão da avaliação está presente em práticas classificatórias com tendências conservadoras e tecnicistas que se tornaram tradição com o passar dos anos (OLIVEIRA et al., 2008). Certamente que não podemos abandonar completamente este modelo avaliativo, pois diversos sistemas que regem processos seletivos como vestibulares e concursos públicos, por exemplo, utilizam esta metodologia. Todavia não podemos limitar a avaliação, única e exclusivamente, a este instrumento. A prova foi apontada pelos entrevistados como sendo o principal instrumento dentro desta função de avaliação. Os licenciandos foram críticos à prova como método avaliativo pontual, quantitativo e decorável, embora também tenham destacado aspectos positivos como o exercício da escrita nas aulas de Ciências.

Os licenciandos ainda identificaram a prova como um instrumento padronizado de avaliação que visa à normatização de práticas escolares e à exclusão de estudantes que se sentem pressionados e frustrados. Nesse sentido, a formação inicial, em uma diversidade de disciplinas, como espaço para a reflexão sobre a avaliação da aprendizagem apareceu positivamente nos resultados da pesquisa.

A avaliação como uma prática de acompanhamento do processo de ensinoaprendizagem, dentro da função formativa (KRAEMER, 2005), também foi contemplada nas falas dos licenciandos. Assim como também a função mediadora (HOFFMANN, 2014), através de falas que expressaram a preocupação dos futuros professores com a avaliação de seus próprios métodos e suas estratégias de ensino. Logo, notamos que a avaliação também é entendida como um momento de reflexão do professor no qual ele consegue um retorno sobre os objetivos estipulados em seu planejamento. No entanto, encontramos ainda vestígios de uma concepção em que o aluno é um agente passivo na maior parte do processo de ensino-aprendizagem.

Entendemos, portanto, que este tema deve ser discutido nos cursos de licenciatura de modo que os futuros professores consigam questionar e desconstruir os modelos 
avaliativos que vivenciaram em suas trajetórias escolar e acadêmica, para que possam conhecer teorias sobre as funções da avaliação da aprendizagem e, a partir daí, organizarem práticas de ensino não excludentes. Somente assim, a avaliação poderá ser vista para além da medição de aspectos cognitivos, incluindo aspectos psicológicos e sociais.

\section{REFERÊNCIAS}

ALÍPIO, A. C. N.; GALIETA, T. Os diferentes processos avaliativos no Ensino de Ciências: quais são as interpretações dos alunos? Revista Brasileira de Ensino de Ciência e Tecnologia, v. 11, n. 1, p. 50-72, 2018. Disponível em https://periodicos.utfpr.edu.br/rbect/article/view/4747. Acesso em: 30/07/19.

BAUER, A.; ALAVARSE, O. M.; OLIVEIRA, R. P. de. Avaliações em larga escala: uma sistematização do debate. Educação e Pesquisa, v. 41, n. especial, p. 1367-1382, 2015. Disponível em http://www.scielo.br/scielo.php?pid=S151797022015001001367\&script=sci_abstract\&tlng=pt. Acesso em: 30/07/19.

BLAYA, C. Processo de Avaliação, Prática Educativa, 2009. Disponível em http://geigestar.blogspot.com.br/2009/11/processo-de-avaliacao.html. Acesso em: 03/05/2018.

DINIZ, B. L. T. A avaliação da aprendizagem por licenciandos em Ciências Biológicas: métodos tradicionais e alternativos. 89f. Monografia (Graduação em Licenciatura em Ciências Biológicas) São Gonçalo, RJ: FFP/UERJ 2017.

ESTEBAN, M. T. Avaliação: uma prática em busca de novos sentidos. 1 ed. Rio de Janeiro: DP et Alii, 2003.

FERNANDES, C. de O.; FREITAS, L. C. de. Indagações sobre currículo: currículo e avaliação. Brasília: Ministério da Educação, Secretaria de Educação Básica, 2007. FREITAS, L. C. de. Avaliação: construindo o conceito. Ciência \& Ensino, n. 3, p. 1619, 1997. Disponível em http://200.133.218.118:3535/ojs/index.php/cienciaeensino/article/viewFile/24/31. Acesso em 30/07/19.

GARCÍA-JIMÉNEZ, E. La evaluación del aprendizaje: de la retroalimentación a la autorregulación. El papel de las tecnologias. Revista Electrónica de Investigación y Evaluación Educativa, v. 21, n. 2, p. 1-24, 2015. Disponível em http://roderic.uv.es/handle/10550/49873. Acesso em: 28/07/19.

GASPAR, M. L. F.; LEVANDOVSKI, A. R. O processo de avaliação da aprendizagem escolar na prática pedagógica. In: Portal Educacional do Estado do Paraná. (s/d) Disponível em www.diaadiaeducacao.pr.gov.br/portals/pde/arquivos/1769-6.pdf. Acesso em: 15/04/2019. GIL, A. C. Métodos e técnicas de pesquisa social. São Paulo, Editora Atlas, 1987. HOFFMANN, J. Avaliação mito \& desafio: uma perspectiva construtivista. $24^{\mathrm{a}}$ ed. Porto Alegre: Mediação, 1998.

Avaliação Mediadora. 33. ed. Porto Alegre: Mediação, 2014.

HOFFMANN, J. L.; NAHIRNE, A. P.; STRIEDER, D. M. Um diálogo sobre as concepções alternativas presentes no ensino das ciências. Arquivos do MUDI, v. 21, n. 
3, p. 90-101, 2017. Disponível em

http://www.periodicos.uem.br/ojs/index.php/ArqMudi/article/view/40944/0. Acesso em: 30/07/19.

JACQUES, B. P. Formandos em Ciências Biológicas: formados para avaliar?. 112f. Monografia (Graduação em Licenciatura em Ciências Biológicas). São Gonçalo, RJ: FFP/UERJ 2018.

KRAEMER, M. E. P. Avaliação da aprendizagem como construção do saber. V Coloquio Internacional sobre Gestión Universitaria en America del Sur. Mar Del Plata, 2005.

LUCKESI, C. C. Avaliação da aprendizagem escolar: estudos e proposições. 19. ed. São Paulo: Cortez, 2008.

Avaliação da aprendizagem componente do ato pedagógico. 1. ed. São

Paulo: Cortez, 2011.

LUDKE, Menga; ANDRÉ, Marli. Pesquisa em Educação: abordagens qualitativas.

São Paulo: EPU, 2012.

MINAYO, M. C. S. O desafio do conhecimento: pesquisa qualitativa em saúde. São

Paulo: Hucitec, 1994.

MORETTO, V. P. Prova: um momento privilegiado de estudo, não um acerto de contas. Rio de Janeiro: Lamparina, 2001.

NETO, A. L. G. C.; AQUINO, J. L. F. A Avaliação da aprendizagem como um ato amoroso: o que o professor pratica? Educação em Revista, Belo Horizonte, v. 25, n. 2, p. 223-240, 2009. Disponível em http://www.scielo.br/scielo.php?pid=S010246982009000200010\&script=sci_abstract\&tlng=pt. Acesso em: 30/07/19.

OLIVEIRA, A.; APARECIDA, C.; SOUZA, G. M. R. Avaliação: conceitos em diferentes olhares, uma experiência vivenciada no curso de pedagogia. Anais... EDUCERE - VIII Congresso Nacional de Educação. Curitiba: PUCPR, 2008.

SANT'ANNA, I. M. Por que avaliar? Como avaliar? Critérios e instrumentos. 16. ed. Petrópolis:, RJ: Vozes, 2013.

SAVIANI, D. Pedagogia histórico-crítica: primeiras aproximações. 10 ed. Campinas, SP: Autores Associados, 2008.

SILVA, R. H. A.; SCAPIN, L. T. Utilização da avaliação formativa para a implementação da problematização como método ativo de ensino-aprendizagem.

Estudos de Avaliação Educacional, v. 22, n. 50, p. 537-552, 2011. Disponível em http://publicacoes.fcc.org.br/ojs/index.php/eae/article/view/1969. Acesso em: 29/07/19. SOUZA, K. R. C. de Avaliação do Ensino Fundamental. 46f. Trabalho de Conclusão de Curso. São Gonçalo, RJ: FFP/UERJ, 2009.

TARDIF, M. Saberes docentes e formação profissional. Petrópolis. RJ: Vozes, 2002. WACHOWICZ, L. A. A dialética da avaliação da aprendizagem, na pedagogia diferenciada. In: CASTANHO, M. E.; CASTANHO, S. (Orgs.). O que há de novo na Educação Superior. Campinas: Papirus, 2000. 